\title{
Grids: A Kraussian Perspective on New Windows for the Church
}

\author{
Jonathan Koestlé-Cate \\ Goldsmith College, University of London
}

\begin{abstract}
Rosalind Krauss's landmark essay of 1979 on the grid form in art characterised the grid in equivocal terms as centrifugal and centripetal, as structure and framework, and most significantly for this discussion, as a vehicle for the conjunction of art and spirit. The grid provided artists with a means to surreptitiously reintroduce the spiritual into an art form that appeared, on the surface, to be wholly material. Taking her essay as its basis this paper looks at the work of two contemporary artists known for their adoption of the grid as a guiding motif. In recent years James Hugonin and Gerhard Richter have each produced a stained-glass window for the church using a grid system, here discussed in the terms set out in Krauss's foundational text. Writing on the grid, it is said, has produced "reams and reams of artspeak" yet little in the way of sustained reflection on this visual tendency in art for the church. This paper seeks to redress this oversight with reference to two particularly striking examples.
\end{abstract}

\section{Keywords}

Grid, art, spirit, stained glass, Rosalind Krauss, Gerhard Richter, James Hugonin

In 2011 the ACE Award for Art in a Religious Context, organised biannually by the British charity, Art and Christianity Enquiry, went jointly to two artists who had each created a small stained-glass window for a tiny rural church in the north of England, each dedicated to the memory of the parents of the church warden. A few years earlier, on a far grander scale and subject to considerably greater media attention, the inauguration of a new window for Cologne Cathedral took place. What links these two occasions is the visual motif chosen by two of the three artists involved: both James Hugonin for the English church and Gerhard Richter for the German cathedral utilised the structure of the grid. There is, perhaps, nothing fundamentally surprising about this. By the nature of their construction stained-glass windows frequently resort to gridded structures, the geography of the design mapped out in the filigree of fine leaded lines or else fragmented by a network of leaded outlines and the bars of the window itself. Where Hugonin's and Richter's windows differ from this pattern is in making the grid itself the subject of the image. In this paper I would like to situate these two works within a particular art discourse of the grid, which will, I believe, shed light upon their efficacy as art objects within an ecclesiastical context. To that end we should take heed of Meghan Dailey's observation that the grid's prolific appearance in art, having "spawned innumerable canvases," has since become the subject of "reams and reams of artspeak" (171). This might seem to invalidate the addition of yet another text to the literary pile. However, it is my intention to respond to what has become a canonic text in this field in order to consider a number of questions pertinent to a discussion of contemporary art in the church that have not to my knowledge been raised elsewhere.

In a landmark essay from 1979, Rosalind Krauss raised the alluring possibility that the grid, as it has appeared within the history of Modernism, has served artists as a means of bridging the widening gap between the sacred and the secular, which have in modernity, she claims, suffered an irremediable 
division. Even though the grid is in one sense highly materialistic, a mapping of surface, it is a materialism that has acted as a conduit to the universal, or the spiritual, as if a slice of some sublime eternity ("Grids" 52). The grid, she declares, is the emblematic form through which the scientific split between spirit and matter and the ideological split between sacred and secular to some extent disappears or, better said, is covered over, with decisive implications for the artist:

Given the absolute rift that had opened between the sacred and the secular, the modern artist was obviously faced with the necessity to choose between one mode of expression and the other. The curious testimony offered by the grid is that at this juncture he tried to decide for both. (ibid 54)

No doubt Krauss would admit to no transcendent reality behind that mode of expression. Indeed, given her blithe assumption, repeated ad nauseum by numerous others since, that modernity represents a final and absolute break between sacred and secular experience, we might expect her analysis to repudiate any and all evocations of the spiritual in modern art. What her approach offers, in fact, is a rather more interesting and promising evaluation of the grid in terms highly apposite to the works we intend to discuss.

Krauss's conviction is that through the processes of secularisation we associate with western modernity, art has ceased to act as a representation of "religious emotion" and become instead a proxy or "refuge" for it (ibid), hence the tiresome but ubiquitous image of art museums as our modern cathedrals. She goes on to assert that, though open to discussion in the nineteenth century, this view of art as the bearer of spiritual values, or worse, a religious sensibility, "is something that is inadmissible in the twentieth, so that by now we find it indescribably embarrassing to mention art and spirit in the same sentence" (ibid). Disregarding for the time being that "we" with which Krauss draws us all into the cynical orbit of the "modern" lover of art anxious to preserve a gap between art and spirit, the point being made is that it is the grid which best embodies the potential to negotiate this difficulty or, as she puts it, "to preside over this shame" (ibid). ${ }^{1}$ Whilst allowing us to assume that we are dealing with the material it simultaneously attests to the immaterial. Agnes Martin is an obvious point of reference, her austere and minimal grids seen by some to be exemplary of a Modernist sacrality. Indeed, it is with Martin's works in mind that Krauss argues for the grid's modernity in both spatial and temporal terms. Spatially flat, temporally static, geometric and ordered, it is, she says, "antinatural, antimimetic, antireal." This triad of negations announces, among other things, the "stasis of the grid," its "anti-referential character" and above all its "hostility to narrative" (not merely passive silence, but the very "refusal of speech"), remaining a uniquely visual domain ("The Originality of the AvantGarde" 54). Krauss thus defines it in a dual sense, as a will to silence and as a kind of ground zero. The first denotes its disinterestedness, purposelessness,

\footnotetext{
${ }^{1}$ Admittedly Krauss presents us with a rather partisan view of the history of modern art here. It would not be difficult to dispute her privileging of the grid as the bridge between sacred and secular; from Kandinsky to Rothko the language of the spiritual, religious or sacred has never been far from the discourses of Modernist art, with or without the grid.
} 
autonomy and aesthetic purity as a cultural object entirely and definitively divorced from nature; the second serves as the reduction to an absolute beginning.

\section{Historical precedents for the grid}

The temporality of the grid, Krauss insists, is resolutely modern, its aesthetic an "emblem of modernity" by dint of its ubiquity in the twentieth (and now twentyfirst) century, yet total absence in the nineteenth ("Grids" 52). The recurrent motif of the grid is therefore synchronous with the processes of secularisation heralded above all by that great thesis of modernity: the death of God. And yet, Krauss argues, the grid presents us with a more complex relation to modernity and the secular than might at first be apparent. Despite its relatively recent appearance in art, Krauss concedes that harbingers of its emergence may in fact be discerned. Aside from its familiar history as a device for measuring and transferring, or for mapping perspectival depth, the two instances she cites are remarkably pertinent to the present-day examples I wish to present as an outworking of her thesis. The first is the study of optics, which can be loosely divided into two strands of research: the analysis of the physical properties of light and the physiological reception of light and colour, the latter clearly of greater interest to artists. Artists were taught by the science of optics that "the physiological screen through which light passes to the human brain is not transparent, like a windowpane; it is, like a filter, involved in a set of specific distortions" (ibid 57). These distortions included the recognition of colour differences achieved through the conjunction and interaction of colours, that is, the impossibility of visually isolating a colour from its neighbour. The relevance of these treatises on optics to the object of our study is that they were invariably diagrammatically illustrated with a grid in order to convey a basic law of science: "the separation of the perceptual screen from that of the 'real' world" (ibid). This difference or separation of real and perceived was mediated by a grid representing the medium or interface between the world and its reception, the source of light and its perception. The second historical precedent is perhaps more surprising, taking up the metaphor of the windowpane rejected in the first: Symbolist art, in which the grid appears as a recurrent motif in the geometrical form of windows. Crucial to the Symbolist window is its significance as transparent yet opaque, as a material means for light to transpierce, and as a source of reflection, literally acting as a mirror. It is the gridded structure of the window's mullions that enable us to see this transmitting and specular representation. Again the window presents us with a perceptual screen, one which is itself an aspect of reality of course, but which serves to separate and define two modes of apprehension: inside/outside, internal/external, nature/culture, and so on.

Krauss draws these historical threads together by declaring, "I do not think it is an exaggeration to say that behind every twentieth-century grid there lies - like a trauma that must be repressed - a symbolist window parading in the guise of a treatise on optics" (ibid 59). That may be so, but the question we must surely raise is what makes this a trauma to be repressed at all costs? Clearly it is the reappearance of the spiritual in the purportedly material. Beneath the material, the spiritual reappears in the guise of Symbolism's emphasis on spirituality and the imagination contra naturalism and realism, but cloaked in 
the legitimacy of science. Is this the shame to which she alludes earlier in the text? There the shame she identifies is a modern embarrassment, one whose inadmissibility in modern scholarly company consigns it to the shadows. And what is the source of this social indiscretion? It is the disgrace that obliges one "to mention art and spirit in the same sentence." 2 The grid presides over this indiscretion, masking and revealing it at the same time. It is laid like a screen over reality, hiding the discomforting presence of the sacred in art, but allowing something of its spiritual residue to seep through. It does so not by dialectically resolving the contradictions of spirit and matter, but rather "by covering them over so that they seem (but only seem) to go away" (ibid 54). In this sense the grid appears to offer what Mircea Eliade once described as a camouflaged form of the sacred. For Eliade such implicit sacredness is the mark of an unconscious residue, a remainder after explicit declarations of faith have disappeared. But it is also rooted in the Nietzschean thesis of the death of God, which, Eliade insists, "signifies above all the impossibility of expressing a religious experience in traditional religious language" (81). The sacred, he suggests, has not disappeared within post-Nietzschean modernity, but has become unrecognisable, expressed in unconventional and non-traditional forms. The importance of the grid, then, appears to be its function as a surreptitious carrier of spiritual or non-material values. It allows an artist to express spiritual qualities without committing themselves to religious motifs. For the modern artist, if Krauss is to be believed, the latter can only be a source of shame and embarrassment, where the former allows for depth of vision without compromising one's reputation. What if, then, we take seriously Krauss's premises regarding the role of the grid, and without embarrassment apply them to two works that readily combine art and spirit, material and immaterial, by virtue of their ecclesiastical contexts?

Before discussing the artworks in question, for those unfamiliar with the work of these two artists some background explanation would be helpful. James Hugonin's painting career has been built upon the slow and painstaking creation of abstract fields of colour in repeating patterns, overlaying a fine silverpoint grid inscribed on gessoed wooden panels. Section by section these grids are filled with tightly interknit patterns of close toned colour, using a compositional method that combines chance and deliberation. He has progressed from a process involving intuitive mark-making to a more calibrated system that follows certain predetermined rules for the placing of each rectangle of colour; this uses a numerical system that distributes colour according to a double oval template and the span of his hand. Once one chosen colour has been distributed across the surface following this strictly regulated method, another is chosen and the process begins again from a different starting point. The result, as Richard Davey explains, is that as each series of colours works its way across the canvas Hugonin's self-imposed rules produce "unforeseen and unpremeditated variations" within "an integrated, interconnected whole" (Hugonin, James

\footnotetext{
2 Even if many of those with an interest in the relations of art and the church, whether Christian believers or not, would disagree with Krauss on this last point, it remains a fact that many within the art world do have a problem with bringing "art" and "spirit" into the same room, or discussing them on equal terms. As recently as 2007 art historians Michael Fried and T. J. Clark declined to participate in a forum on art and religion on more or less the grounds that Krauss describes. Their precise words were that it would be too "painful" to participate in a discussion linking religion and art in any positive manner (Elkins and Morgan 110).
} 
Hugonin [2010] 6). For the window in St John's Church, Healey, this system for painting was converted into 2,160 small rectangles of translucent coloured glass held suspended between two sheets of clear glass upon which a grid had been sandblasted. Of the two Gerhard Richter is considerably more well-known, recently honoured with a retrospective of his career at Tate Modern. Although eclectic in his output, like Hugonin he is primarily a painter, his earliest experiments with the grid format dating to 1966, when he first began to produce large-scale paintings based on commercial colour charts produced by paint manufacturers. For the Cologne project Richter's commission was to replace a nineteenth century window destroyed in World War II (and unsatisfactorily substituted by a decorative design in 1948). The resulting window comprises a randomly distributed modular grid of 11,500 hand-blown squares of glass in 72 colours that accord with the palette of the cathedral's extant Medieval windows, the randomness achieved using a specially designed computer programme. Unlike Hugonin's systematised distribution of colour, this produces accidental colour relations via a process of chance, in order to eschew any possible figuration or pattern. In fact, the results are not entirely haphazard, with elements doubled and whole sections repeated in reverse, and certain coloured squares deliberately altered to avoid any misconstrual of image. But the overall effect is of random configurations of colour.

Both artists have benefitted from modern techniques of stained-glass production by which coloured glass is sandwiched between clear glass, obviating the need for the leaded supports typically associated with the medium. Without such technical advances the aesthetic choices integral to their work would in fact be untenable. More significantly, the absence of lead allows for the tight juxtaposition of coloured segments. The delicacy of Hugonin's gridded works in particular would suffer from the extraneous interference of material structures ancillary to the image itself. Richter's window, by contrast, is necessarily disrupted by the ribbed casement of the pointed and elaborate gothic tracery. In effect a double pattern is at work, in which the one could be regarded as interfering with or disrupting the other. Theirs is an awkward alliance and one can sympathise to some extent with the criticisms that were raised against the appropriateness of Richter's solution to the context. Hugonin's design, by contrast, competes with no restraints other than the physical frame of the window cavity.

\section{From trauma to scandal: the Richter controversy}

The trauma disclosed by the grid found new expression in the story of the window for Cologne Cathedral, a trauma that elicited not shame as such but something closer to scandal. Here it was not the reappearance of the spiritual in the material that was the cause of objection but something like the appearance of the secular in the sacred. The random abstraction of the grid provoked a bitter controversy, exposing the difficulties of this motif when introduced into the church. Publicity surrounding the commission focused on the hostile reception it received from Cardinal Meisner, the Archbishop of Cologne. At the heart of Meisner's criticism was his perception of the work's impropriety for a Christian place of worship, as if abstraction, or perhaps more incisively, Richter's particular brand of abstraction, failed to convey a quality of sacredness apposite to a Catholic cathedral. What disturbed him was not the window's abstraction as 
such but the computer-generated arbitrariness of the abstraction. To put it in the terms of Krauss's essay, if the grid negotiates a tentative rapprochement of art and spirit, for Meisner this compositional subjection to chance singularly failed to reflect the spirit of its Christian context, its abstraction deemed to be more appropriate to an Islamic or Judaic site. This misleading reading of the work as an arbitrary form of decorative abstraction was countered, in the pages of Artforum and elsewhere, by Benjamin Buchloh, Krauss's October colleague and the critic most closely associated with the artist. In his defence of Richter's window, Buchloh noted that the allegedly "merely decorative" had become "a rather invested, coded, and embattled field indeed" ("Gerhard Richter, Cologne Cathedral" 306). In response, Buchloh frames Richter's colour grids within a tradition of diagrammatic, as opposed to decorative, abstraction yet adds that this schematic approach, already disrupted by its odd configuration within the gothic tracery of its ribbed frame, is subject to a counterforce of "aleatory chromatic constellations" (Larner, Morrill and Phillips 67). What Buchloh proposes here is a dialectic, not of art and spirit, but of structural "confinement" and the freedom of "random chromatic distribution" (ibid 68) which, as we will see, is a significant aspect of the grid's modus operandi.

Despite his approbation, however, for Buchloh too the window prompted uncomfortable associations of art and spirit. If, for Meisner, the scandal of the new window was the lack of consonance between art and the spirit of its ecclesiastical home, for Buchloh, and others similarly vexed by art produced for the church, but for rather different reasons, it is the conjunction of art and religion that is the source of contention. Although Buchloh is willing to confront this religious factor, it is only from a defensive position. He wonders, for example, to what extent the art object should be decontextualized, noting that at its inauguration the window could not be separated from the event nor differentiated from its context. He goes on to ask whether the religious spectacle that unfolded at its consecration should be treated as part of the work or incidental to it. And bearing in mind that as a consecrated object the window was officially blessed, he ponders the effect this might have on the meaning ascribed to the work. To his credit Buchloh appears to distance himself from the reactionary response of those "art worshippers" who would insist on the window as "a work of art in its own right" ("Gerhard Richter, Cologne Cathedral" 308), yet it is clear that he is himself uncomfortable with the fact that this outstanding achievement of Richter's, for which he has such admiration singling it out in the pages of Artforum as the artistic highlight of 2007 - is regrettably vulnerable to any number of religious associations or readings because of its location. In the background to his review, as a kind of critical constant, is a sense of that reservation typifying the art world concerning the contested notion of the church as an appropriate site for contemporary art: that the sacred context threatens to pollute the object of art with an unwarranted religiosity. Hence, the justification for the idea that it might be desirable from the perspective of art appreciation to separate the work from its context. For an artwork of this kind this is so extraordinary a proposition that we can only conclude that it is the religious context that poses the particular problem. However, this concern is not reflected in Richter's own comments, for whom, perhaps surprisingly, the window is what it is by virtue of its ecclesiastical context. Richter is rather more humble in his evaluation of the window than 
many of his commentators, recognizing the significance of the building and all that it represents, for which he believes his window provides a beautifully rendered complement, to the extent that he is prepared to say that it may not even be art as such. Such a comment must strike the art world as a kind of betrayal, but equally reveals Richter's willingness, against the grain of his critics, to accept as inevitable the conjunction of art and spirit that such a work entails and the religious readings that it invites:

But here with the cathedral window we're talking about something quite concrete, something real, and it's a very special location which carries a greater burden of history and importance than almost any other. It is all so overwhelming that any supplementation with modern art often comes across as inhibited, false, silly or kitsch. In order to avoid this danger, I have taken the place as it is: what does the cathedral look like, how is it used? And in so doing, I've avoided wanting anything special. So: no depictions of saints, no message, and in a certain sense, not even art. It was just to be a radiantly beautiful window, as good and beautiful and with as many meanings as I could make it here and now. (Richter in Obrist 123)

Despite Richter's openly acknowledged antipathy towards religion, it is worth recalling that in an interview some ten years prior to his acceptance of the commission, he admitted that he had become "less antagonistic to 'the holy,' to the spiritual experience," willing to concede not only that it is something inherent in human experience, but that it is even a necessary quality (Richter 365). It is not clear what he understands "spiritual experience" to mean, but we can presume that it presupposes something greater than material life or aesthetic perception. At the very least it infers that an ecclesiastical commission of this kind demands a degree of humility not otherwise expected of the artist. Indeed, in keeping with the weight of responsibility that comes with such commissions it was Richter's conviction that contemporary art should neither assert its presence nor foreground its own criteria in such a context. Instead, as we can see from his conversation with Hans Ulrich Obrist, his objective was simply to create a beautiful window. Although the sceptical among us might read this as a veiled denial of any overtly religious content, among the "many meanings" the window holds, intended or unintended, there can be no doubt that Richter was perfectly aware that ultimately what could not be avoided were associations with light and the symbolism of light, and by virtue of its sacred context, with spiritual as much as aesthetic qualities. Consequently it has been argued that it positively upholds a biblical and Neoplatonist tradition of "light metaphysics" (Museum Ludwig 123) that corresponds to the important role played by stained glass in the Medieval imagination, the translucency of glass providing an apt metaphor for the porous border between divine and earthly powers, a visible manifestation, if you will, of the presence of the invisible God. This capacity to express spiritual values and enable spiritual experience through art and architecture has been one of Christianity's strengths, since, as Bishop Harries has put it, in Christianity "the material and the immaterial, the visible and the invisible, the physical and the spiritual interpenetrate one another" (87). Far from covering over the contradictions of spirit and matter, then, when the 
grid becomes a channel for light it necessarily becomes a medium for something other than itself: the optical effects of light and colour certainly, but also, potentially, a vehicle for the spiritual or sacred. Furthermore, in response to those for whom Richter's window reveals a marked disparity of object and context, thereby arrogating a conflict of material and spiritual interests, whether as insufficiently religious (Meisner) or over-inflected by religion (the concerns of a reluctant art world), it may be this very incongruity that guarantees its deliverance from purely material values. Writing on the window, the Jesuit priest/curator Friedhelm Mennekes, always to be relied upon for a contrary position, stresses its inexorable contextualisation, describing it approvingly as a Fremdkörper, a foreign body, within the gothic space (55). For Mennekes it is not so much the arbitrary configuration of Richter's heteroclite creation that arrests his attention, but rather its capacity to act as a screen or "membrane," for diffused light of course, but also for the transformation of the material into the spiritual, for which glass is a peculiarly effective conduit (ibid). At the very least Richter's diagrammatic abstraction avoids the interpretative limitations of figuration; at best it initiates any number of cognitive, emotive, aesthetic or indeed, religious responses.

\section{Abstract-luminism}

Critics are less reluctant to ascribe a spiritual quality to the work of James Hugonin. Sister Wendy Beckett, admittedly not the most objective of voices, describes his art as "essentially contemplative, spiritual to its heart" (18). But other, more ostensibly secular critics share her opinion, though often couched in phenomenological rather than spiritual language. It is certainly the case that analogies of light are more easily identified in his grids. Long before the stained glass window was mooted as a possibility Hugonin's paintings were habitually equated with light, both by the artist himself and by those writing on him. In an early text he expressed a desire to achieve through his paintings a sense of light "as an independent entity"; not so much a luminous effect of colour but something like a transmutation of colour into light (Hugonin, Repeat). Others have noted how each tiny mark of colour, acting in concert with its immediate neighbours, reveals a translucent and shifting quality of light. With these thoughts in mind it is not surprising that Hugonin was asked to create a stained glass window, directly combining colour with light as a logical and natural outcome of his artistic explorations. Hugonin's instinct for colour as light is reiterated time and again in writing on his work, described as a contrast of physical materiality and ephemeral temporality, echoing that contrast of spirit and matter so central to the grid. Simon Morley has coined a term for the kind of painting which deals with precisely this contrast of the material and immaterial, ephemeral or spiritual. He calls it "abstract-luminism," a painterly effect of "light as surface" evident in the paintings of Rothko, Newman, and Martin, but exemplified above all by Turner ("Light as Surface" 30). Abstract-luminism in painting seeks to evoke an intense quality or experience of light, in a play between the materiality of the object and its capacities to induce a sense of immaterial transcendence in the experience of the viewer. The physical objecthood of the work - its framing, structures and supports - is supplemented by a veritable dematerialisation effected by, or perhaps despite, those very same material frameworks. Clearly a direction for such an argument is towards what 
some have called the contemporary sublime, but Morley makes the more interesting point (at least for the arguments being presented here) that abstractluminism evokes a sense of the spiritual as psychological or inner experience that extends far beyond strictly religious parameters, and a notion of sacredness that exceeds conventional ideas of the sacred (ibid 32). Morley selects for particular approbation the paintings of James Hugonin, in which the contrast between the fine silver-point grid and the rectangles of delicate colour results in "a compelling dualism" of material properties and atmospheric effects:

Close-up the viewer is held by the finite intricacies of the grid, but seen from a distance the whole surface appears to dissolve into a slowly pulsating and deeply affective space. Neither state seems definitive, and one senses movement and ambiguity as the finite and infinite interplay. How to account for this arresting effect? While metaphorical readings come readily to hand, work like Hugonin's in a way actually enacts a metaphysical reality. On a symbolic level the grid implies order and reason, while the luminous veil suggest a more inchoate state of desire or spirituality. (Ibid 32-34)

Morley's adoption of the figure of the "luminous veil" is particularly telling, as a form both porous and opaque, revealing and inhibiting, as coloured glass can be (although it is of course the paintings that are the object of Morley's attention). In an article published the previous year on the sublime and the beautiful, Hugonin again appears as exemplary. Here Morley notes the paradox of "a semiological system" based upon certain structural determinants but ultimately defined by "the amorphous and the indeterminate." Such works, he continues, "juxtapose the solidity of geometric form and/or surface facture with a quality of luminous spatialisation" ("The Sublime and the Beautiful" 14). In this text luminosity again appears as "a diffuse chromatic mist or veil." A painting by Hugonin, seen from a distance, first presents "a grey, stone-like façade" but then, when approached more closely, "dissolves into a shimmering, subtly coloured veil or luminous container" (ibid 15). Closer still and the canvas reveals an intricate grid in-filled with an apparently irregular arrangement of colours. Here the dualism described in his later article is prefigured by a three-stage process, first identified in 1971 by Kasha Linville as a means to describe the phenomenological experience of Agnes Martin's painted grids and later adopted by Krauss in her own work on the artist. In a now celebrated essay Krauss describes the moment of luminous dissolution as "the /cloud/," a term and idea deliberately chosen to evoke atmospheric effect through phenomenological engagement, one which changes according to the viewer's perceptual field relative to their distance from the art object (the slash indicating the significant positioning of the middle term in a tripartite relationship of materiality, atmosphere and opacity). Morley acknowledges his indebtedness to Krauss but adopts his own vocabulary of abstract-luminism in order to better attend to the particular effect of Hugonin's paintings. Writing on Hugonin for an exhibition of the artist's work, Mel Gooding takes this idea a little further, encapsulating the spirit of this inquiry into the grid: 
In the paintings of James Hugonin it is as if the multifarious light, shadow and colour of the Northumberland hills where he daily lives and works is refracted through a prismatic window and diffused into a vibrant, barely differentiated luminosity. The eyes encounter a singular dazzle, like that we experience when looking intently across a field of grass or a sheet of shimmering water. The optical effect is contradictory: a restless stasis, a motionless kinesis. (Hugonin, James Hugonin [1991])

Within this single paragraph several key themes appear: windows, optics, and luminosity. As Gooding's text continues he draws closer and closer to our object of study, finally making an explicit reference to the optical effects of stained glass windows: "Like the multitudinous lights of a stained glass window combining to effect a unified picture, the 'minute articulations' of pure colour in a Hugonin painting coalesce into a single radiance..." (ibid). For Gooding, the "dynamic lucency" of this radiance is not simply orientated towards delivering an impression of the sensible world. It is in fact "a means to spiritual apprehension." As such, Gooding argues, "his true purpose may be properly termed anagogic" (ibid), by which he infers an allegorical or spiritual interpretation of the world, the "dazzle" of his works reflecting the transcendent through a kind of saturated visual experience somewhat akin to that employed in the theology of Jean-Luc Marion as "bedazzlement" (Marion 203).

It is clear, then, that Hugonin's work not only lends itself readily to a stained glass commission but also to the language of the transcendent, spiritual or sacred. As such, Morley argues that the "luminous aura" of paintings like Martin's or Hugonin's in fact offer an experience beyond language, including the language of painting itself ("The Sublime and the Beautiful" 16). He highlights, as a possible descriptor for this beyond-language, the juxtaposition of the optical "the visual field experienced as a luminous or cloud-like space" - with the tactile - "the material fact of the object registered through surface and geometry" (ibid). The double play of the grid in such works may be reduced to purely phenomenological terms as these, reflected too in Krauss's preferred reading of Martin's paintings, or they may be turned toward more allusive and indeed spiritual interpretations, as Morley hints at with his description of a "luminous aura" or "veil." As Krauss's essay teaches us, the artist's adoption of the grid allows optical means to be turned to sacred ends. This way of reading or, better said, experiencing a work is given literal expression when the gridded network of colour is no longer bound to its opaque canvas base but given translucency through the medium of glass and addition of light itself, even if that opticality takes a different form in the translation from one medium to another. Due to the window's small scale and intimate nature the gridded lattice of colour loses something of the luminous aesthetic quality so prized by Morley. But this loss is compensated for by the passage of light itself through the work, which reanimates this sense of abstract-luminism through the variegations of fluctuating light. Furthermore, if the discourse surrounding Hugonin's paintings describes their genesis in the artist's experience of light and for the viewer their transformation of colour into light, with the window for St John's the inverse appears to be true: light is transmuted into colour. Thus the tacit conjunction of art and spirit, hinted at in the optical effect of Hugonin's paintings, achieves overt expression in the window through its ecclesiastical setting. A significant aspect of 
this setting is that, unlike Richter's monumental creation, the window at Healey is on a human scale and at eye level. Close enough to touch it is also open to close inspection, where imperfections and air bubbles trapped in the glass change our perspective of its formal order and perfection. In the paintings colours are fixed and it is our proximity to, or distance from the surface that effects a change in our perception of them. But with the window, shifting our viewing position has an effect upon the colour values themselves, as do the variable atmospheric conditions outside.

This play between the tactile and optical, material and immaterial, phenomenological and spiritual, numbers among the many paradoxes embodied by the grid, which operates according to simultaneous yet antithetical mechanisms. Thus we find a whole series of binary terms, not only in Krauss's text but in others writing on the grid, that are clearly discernible in the work of Richter and Hugonin. Two groupings are particularly informative for this discussion: centrifugal and centripetal, and structures and frameworks.

\section{Centrifugal and centripetal}

Drawing upon ideas she credits to John Elderfield, whose earlier study of the grid in the pages of Artforum was a formative influence upon Krauss's own essay, an important distinction to be made is between the centrifugal and centripetal dynamic of the grid. The former claims for the grid a limitless, extensive quality, as if it signifies a fragment of reality held in check by the borders of the picture plane yet with the capacity to continue indefinitely. Centrifugally it extends imaginatively outwards, from the work of art, "in all directions, to infinity," thereby "compelling our acknowledgement of a world beyond the frame" (Krauss, "Grids" 60). Many of Mondrian's works attest to this perception, analogous to observing a landscape through a window, "the frame of the window arbitrarily truncating our view but never shaking our certainty that the landscape continues beyond the limits of what we can, at that moment, see" (ibid 63). This centrifugal dynamic is especially clear in the serial extensity of repeating motifs, whereby the grid appears as an infinitely extendable network of homogeneous and contiguous relations governed by the logic of repetition. Yet equally the grid expresses a centripetal sense of completion. Centripetally, the grid begins from the outer limits of the artwork and draws inwardly, intensively, "an introjection of the boundaries of the world into the interior of the work" to create "an autonomous, organic whole" (ibid 61). Here once again Mondrian is instructive, his works an attempt to create a world of geometric certainty distinct from the world, one governed by the implacable logic of the vertical and horizontal. Significantly, in many of Mondrian's iconic works the thick black structural lines actually stop short of the canvas edge, thus disavowing a sense of continuity beyond its outer limits. Instead, as Krauss puts it, "this caesura between the outer limits of the grid and the outer limits of the painting forces us to read the one as completely contained within the other" (ibid 63). We find a similar dynamic at work in many of Agnes Martin's paintings, whose inner intensity or sense of completion is heightened by their containment within a frame or margin of unmarked canvas.

Amy Goldin's early essay on the grid takes the uncompromising and somewhat doctrinaire view that grids are intrinsically centrifugal, except where emphasis is placed upon elements of framing (52). Krauss, on the other hand, 
shows a distinct allegiance to the autotelic function of the grid in her essay, disclosing her privileging of its centripetal character. That at least is the verdict of Andrew McNamara, in his study of the grid in avant-garde thought (79, n.71). McNamara's own take on the grid is that it discloses a fundamental ambiguity in its potential to be read both centrifugally and centripetally, the former "an external and extendable logic," the latter "a logic of self-contained formal repetition and inner self-consistency" (74). On the one hand, the grid offers a kind of serial extensity and applied rationality; on the other, an inner intensity introspectively independent without reference to anything external. Either reading is possible, but for McNamara as opposing readings they render Krauss's conclusions about the grid's testimony to modernity questionable and, if adopted, a challenge to the clarity of the avant-garde utopian thought of his discussion. The crux of the problem is that the centripetal and centrifugal perspective of the grid can never be read simultaneously, for the very particular reason that each signifies a contrary position or impulse that cannot be reconciled within modernism. The implication in McNamara's text is that centrifugal and centripetal are allied to specific phenomena that cannot be merged: "the aesthetic and the material, the mystic and the rational/functional, the scientific and the spiritual" (75). This ambivalence is one that Krauss also acknowledges but, contrary to McNamara's assessment, it is clear from her analysis that these apparently equivocal forces may coexist within the same image. Indeed, her point is that it is precisely this "schizophrenic" condition of the grid that defines its enigmatic status within modernity, the very source of the shame that dispels all such utopianisms ("Grids" 60). Krauss's subtler argument sees the paradox of the grid in its capacity to embody material and spiritual elements simultaneously, whether centrifugal or centripetal.

The two artists under discussion seem indebted to and proponents of just such ambivalent possibilities, yet without consigning their creations to one or the other of these two distinct poles. Both begin with a mathematical or systematic foundation, yet the end result is a composition of random and unpremeditated variations of colour. Even if we are led to conjecture that in the one a centrifugal dynamic predominates, while the other exhibits a more obviously centripetal character, we should resist the temptation to align one firmly with the material, rational and scientific, and the other with the aesthetic, mystical and spiritual. The impression given by Richter's squares, as they appear between the gothic ribs, is that theirs is a proliferating series, only held in check by their architectural frame. One imagines that were another window to be opened in the wall they would appear there too. No clearer example of this centrifugal tendency can be found than in the parallel project that accompanied the window's inauguration. Held in the Museum Ludwig, Cologne, 4900 Colours presented a series of Richter's colour chart paintings using the same 72 colour palette, including a small series of incrementally expanding canvases. Beginning with a tiny square canvas block of 4 colours, then 16 , then 64 , then 256 , then 1024 , by the arrival of the largest only the constraints of the gallery space precluded an infinite continuation of this expanding series. Hugonin's window, by contrast, is more obviously centripetal. There is a completeness about it that suits its commemorative purpose, due, in part, to its size and framing within the heavy stonework of the church wall. One finds a similar centripetal character in many of his paintings, bordered as they are by an area of blank canvas, which 
serves as a framing device for the gridded image within. "The paintings are very much themselves," says one critic, "irreducibly visual in their means, not 'standing' for something else by dint of illusion" (Kemp). These are pictures, he continues, "whose only reference is to the hermetically sealed reality of their own existence." And yet, in the same breath, he concedes that "they are immensely rich in resonances which extend their significance beyond their own visual properties," thus belying a purely centripetal reading. In either case both Richter's and Hugonin's use of the grid, though inclining towards contrasting dynamics, resists being limited to either a material or spiritual reading, thereby reiterating that conjunction of art and spirit discussed by Krauss.

\section{Structures and frameworks}

It is also from Elderfield's text that we derive an important distinction between "structures" and "frameworks." Frameworks provide an underlying organising schema for superimposed images or marks, the grid acting merely as an armature to the in-filling of colour; structures constitute the entirety of all that is displayed. Remove the grid in Martin's paintings or Hugonin's earliest works and nothing remains bar the empty surface of the canvas, whereas in the work of an artist like Chuck Close the grid provides the support or organising principle for the image. If the distinction implies flexibility on the one hand and rigidity on the other, of far greater significance is the possibility for the determinate structure of the grid to become a framework for spontaneity: "It serves something of the function of a strict verse form, like a sonnet, or a fugal structure in music, supplying the underlying constraints with which the freedom of choice works to achieve instinctual articulation, rather than collapsing in visual anarchy" (Kemp). Acting as both "a prison in which the caged artist feels at liberty" (Krauss, "The Originality of the Avant-Garde" 56), and a "visual anchor" (Lippard), the principle of the grid is to provide "an arbitrary framework on which to build an entity, a self-restrictive device by which to facilitate choice" (ibid), whereby self-imposed limitations enable creative but unpremeditated results. The metaphors of anchor and cage posit a sense of restrictive grounding that nonetheless allows for play, suggesting that the grid delineates a repetitive structure of tight control, yet at the same time attests to a certain limitlessness (Dailey 171).

The argument is sometimes made that commitment to the grid can only stifle invention and foster repetition since "structurally, logically, axiomatically, the grid can only be repeated" (Krauss, "The Originality of the Avant-Garde" 56). As Krauss observes, repetition is all-too-frequently contrasted to originality, a pairing which privileges the latter. However, the counter argument she makes is that inventiveness occurs through repetition. This is precisely Hugonin's method. His process draws complexity from the repetition of a simple system, strictly adhered to. He describes it as a "richness of modulation," (South Bank Centre 26) taking as his model minimalist music whose repetitions are subtly modified by degrees of variation. This repetitive structure creates a space in which the listener is able to "lose" themselves in the music, and this, he declares, is comparable to the experience of the viewer before his paintings (ibid 30). This would suggest that the effect of Hugonin's tiny marks, as an index of sunlight's intangible flicker, relies upon the implementation of systematic order, augmenting a visual experience beyond the rigidities of the grid: 
The grid I use is a forming principle, a structure to work with and to work against. It is a systematic structure imposed upon the surface, but if I use it inventively, it gives me tremendous freedom to create complexities of rhythm and pattern. I need something stable: the very regularity of the grid is needed to oppose the irregularities of the rhythms. All of these configurations that I put down are intuitively arrived at, they do not conform to any pre-planned system. I always want to make something which will defy the system I have initially imposed - the system of the grid itself. (Ibid)

Against the strict rigour of the grid his lozenges of colour assert an independence inimical to the systematisation of the rules that generate them, opposing both grid and picture plane. "They create," observes Yetton, "an ambiguous space floating in front of and behind that plane" ("The Abstract Ideal and the Sensual World" 24). This is notably so in the case of the window where the two are in fact separated by layers of coloured and gridded glass, adding a certain threedimensional depth also apparent in the paintings but as an optical effect produced by their colour field. The paradox of the grid becomes apparent in the relationship between a material plane and the colour that populates it, between the material restrictions of the grid and its aesthetic possibilities. If the formulaic discipline of the grid reduces the scope of visual decision-making available to the artist, it compensates for this restriction by allowing a greater focus upon the colour relationships that emerge. And indeed, it is this predominance of colour that marks out the field of Hugonin's work, visible in the optical effect elucidated so well by Morley. Yetton describes this effect as a "battle between the grid's attempt to establish a picture plane and colour's attempt to create a space" ("James Hugonin: Paintings 2004-2008" 8), but I would argue that battle is too adversarial a term for what is, in fact, a recursive interplay between material facticity and atmospheric effect. Morley hits nearer the mark when he describes the dualism between the enjoyment of their material form close to, and their luminous dissolution when seen from further away, as "Hugonin's dialectic" ("Light as Surface" 34), but only inasmuch that, as Krauss also insisted, no aesthetic synthesis is achieved by means of this conjoined facticity and luminosity, no resolution of the contradictions and tensions of spirit and matter. Ultimately, then, it is via, rather than despite, the mathematical framework of the grid that it comes to be associated with something other than purely material values.

\section{A will to silence and a new beginning}

In Goldin's early assessment of the grid, its nonfigurative and endlessly repeating character is said to induce "a zone of silence" (52). This is the silence decreed by Krauss to be the mark of the Modernist grid in all it opposes or negates. In a 1966 essay by Susan Sontag, The Aesthetics of Silence, which may have been an influence on Krauss's own thoughts, four possible modes of this modern silence may be discerned in the work of art: as absence or renunciation, as a mark of completion, as an openness to continuity, or as a form of rhetorical emphasis (19-20). It is this first mode that appears most frequently in discussions on abstraction and art's relationship to the spiritual. For example, in an essay by Buchloh entirely devoted to matters of silence in Richter's work, silence is 
posited as a form of "aesthetic withdrawal" ("Richter's Abstractions: Silences, Voids, and Evacuations" 8). One of the factors for proscriptive silence, he suggests, originates "in the recognition that certain conventions of speech have become historically dysfunctional” (ibid 12). Buchloh's discussion centres upon the part played by Richter (along with artists like Baselitz, Kiefer and Beuys) in Germany's postwar cultural rehabilitation, but it resonates too with Eliade's elision of "traditional religious language" discussed earlier. The silence of the grid finds too a comparable equivalent in the refusal or renunciation of religious narrative, instituting a form of "negative aesthetics that resonates with the authority of the prohibition on graven images in the Old Testament" (ibid 8). Was it a visual abjuration of this kind that motivated Richter's choices when it came to the Cologne commission, or is the silence it enshrines of a different order? According to his own testimony, Richter claims no such Adornian nor biblical precedents. His determination to renounce all narrative - "no depiction of saints, no message, and in a certain sense, not even art" - was motivated above all by his desire to supply the cathedral with an effective solution to the problem of incorporating a modern design into the gothic space. Having stumbled upon the grid more or less by chance as a solution to the aesthetic challenge of the window, the work becomes neither a matter of representation nor decoration, but colour and light for which the artwork is but a medium. The silence of meaning is reinforced by its process of creation, with colours randomly distributed by computer. This system persistently undermines efforts to find patterns or meaning despite, as Eliza Williams puts it, "the constant urge to do so" (Williams 86). In the cathedral window the flatness perpetrated by the grid in Modernist painting is enforced by the deliberate lack of pictorial representation. Thus it denies any "illusory spatiality," no escape from the real space where glass traditionally offers a glimpse of the transcendent alongside the earthly figures of saints and patrons. Nevertheless, the particular nature of its ecclesiastical context inevitably generates its own associations. One local priest writing on the window has taken the opportunity to interpret its randomness "as a cypher for the unexpected, the mystery that is beyond humankind's power of comprehension" although he is keen to stress that it conveys no specific message (Sauerborn). But even Richter himself, rather surprisingly, admits to an attempt to convey "divine order behind seemingly random occurrence" (Rigney 46). If the colour chart paintings, the antecedents of the window, are "pure visual objects" (Larner, Morrill and Phillips 127), as Richter claims, endowed with a "beautiful meaninglessness" (Temkin 32), without illusion, saying nothing, and evoking no associations, the same simply cannot be said for the window, not so much for its replication of the colour grid but for its functional quality as a medium of light. If the grid is, in Krauss's terms, autotelic, i.e. fully containing within itself its purpose or meaning, when transposed to the larger context of the cathedral it also finds itself ineluctably part of some larger framework of meaning.

In comparison with Krauss's hopes for the abstract grid (as disinterested, purposeless, autonomous and aesthetically pure), the cathedral window is arguably partial, purposive, contextual and coloured by its aesthetic environment. This liberates it from a kind of dogmatic Modernism but makes it susceptible to any number of interpretative assertions. Much of the rhetoric surrounding the work does little to reflect a will to silence, with praise 
sometimes couched in the most overblown hyperbole, such as this from Barbara Schock-Werner, Dombaumeisterin or Master Builder of the cathedral: "The vitreous wall of colour with its beguiling light has dispelled all ornament and seems to contain everything that has ever been said about spirituality, light and colour" (Museum Ludwig 116). In Schock-Werner's description the window is replete, indeed overcrowded with narrative content. Yet if the function of the window is "inevitably charged" with content, as one writer insists (Diederich in ibid 106) then it cannot entirely avoid the imposition of narrative. Whatever silence is at work, it cannot be considered a pure visual silence, nor an antiaesthetic one, however much Buchloh insists upon Richter's "anti-aesthetic scepticism" or "pictorial anti-aesthetic" ("The Chance Ornament"172). No doubt to Buchloh's disapprobation, a credible allusion has even been made to the ideas of beauty associated with Thomas Aquinas - integrity, proportion and clarity (sometimes translated as wholeness, harmony and radiance) - which the window is said to embody (Museum Ludwig 129).

Hugonin's window presents a very different acoustic, while still satisfying an aesthetic will to silent contemplation. Richard Davey, one of Hugonin's more perceptive interlocutors, has remarked upon the "spiritual quietness" his paintings share with Agnes Martin's, but notes a significant difference too. If Martin's works are orientated towards that experience Krauss christened "the /cloud/," Hugonin's are more specifically concerned with "the experience of colour and light in its own right" (Hugonin, James Hugonin [2010] 26). These "small shards of incarnated light" are, he proposes, "apparently caught up in an interior, self-contained world" (ibid 26, 19), their will to silence suggestive of a withdrawal into their own space, concerned neither with representations of visual reality nor with optical effects. In fact, numerous writers, Davey included (hence that "apparently" with which he qualifies his statement), attest to both a phenomenological engagement with these works and to an external world that exceeds such strictly purist parameters. For example, reference is continually made to the landscape that inspired them, by the artist himself and his interpreters, the inference being that they do not simply internalise a quality of light, but reflect the atmospheric conditions of their particular place of making. If the subject of Hugonin's paintings is "the fickleness and instability of light" it is one he associates specifically with the Northumberland of his home (South Bank Centre 30).

Furthermore, the silence of Hugonin's paintings is coloured by a kind of visual "noise." If they are "all working towards a stillness," as Hugonin claims, it is one "that contains within it innumerable minute changes" (ibid 26). These subtle, rhythmic shifts are responsible for the way his paintings appear to shimmer. But they also introduce a note of modulated change. As such, they are frequently described as "quietly musical," their colour distribution compared to musical notation. The composer, Gavin Bryars, who was once commissioned to compose a piece to accompany an exhibition by Hugonin, has argued that it may be his work is best approached through a musical sensibility. In conversation with the artist Bryars recognised in his references to "rhythm of colour," "equilibrium," and "point of stillness' equivalences to musical creation (Bryars 72). Despite differences of scale and medium all these aspects are no less evident in the window. If Richter's window betokens the silence of random nonfiguration, a resistance to and refusal of dialogue through the avoidance of 
any pictorial narrative (and we have already questioned that presumption), Hugonin's is aural: the commemorative score of a life. But neither it, nor the cathedral window, may lay claim to the purist autonomy of the Modernist work of art. As Davey reminds us, unlike a painting, a window can never be a selfcontained object (Davey 20). It is a medium for light, bound to a specific architectural context, which includes, in the case of Hugonin's window, a clearly commemorative function, indicated by the plaque placed beside it. When considering these two windows for the church, then, silence as internal, selfcontained, even spiritual, must be set against their context and conditions of reception. Here, the grid as a vehicle for disinterestedness, purposelessness, autonomy and aesthetic purity hardly seems to apply. That such language continues to determine ideas about church-based works, however, is clear from the most recent commission of stained-glass windows for Reims Cathedral (incidently a commission that had at some point been rumoured to have been offered to Richter). Writing on Imi Knoebel's six abstract windows, Martin Schulz argues for an awareness of distance or difference between them and the church. They have, he insists, their own "aesthetic autonomy" and "independent history," and thus a "primary artistic individuality" (56). Individuality they certainly have, but it is neither primary, autonomous, nor independent. Schulz goes so far as to stress that these are works that happen to be in a church, but are not works of "church art" (ibid 57). Although we can understand what he means, having encountered similar rhetoric in relation to the Cologne commission, it is obvious that an agenda is at work here, testifying to a pressing need to establish a division, once more, between art and spirit. Gottfried Boehm offers a more realistic assessment, in his discussion of another church windows commission, completed in 2009 by Sigmar Polke. Taking on a commission of this kind is a risky business for an artist, he says, since what cannot be avoided is the inevitable relation of the works of art to the architectural space and its theological imperative (151). This will undoubtedly affect the reception of the artworks, which simply cannot lift themselves free of their architectural support nor entirely liberate themselves from its inherent creeds.

In conclusion, one final point is briefly worth making. Krauss argues that each incarnation of the grid announces a reduction to an absolute beginning. The unique capacity of the grid, she avers, is to always mark a beginning, no matter how often it has been done before, because it signals a return to a kind of ground zero upon which to build invention. It is for this reason that each new "discovery" of the grid heralds a recrudescence of art ("The Originality of the Avant-Garde" 54). Krauss proposes that in the silence enforced by the grid what many artists thought they could hear were the origins of art (ibid). That idea might seem to belong to an earlier utopianism. Nevertheless, a curious parallel can be found in Sontag's aforementioned essay on silence. Her opening line authoritatively declares that "Every era has to reinvent the project of 'spirituality' for itself" (Sontag 3). By spirituality she lists a broad number of possibilities, but above all notes the central role played by art: "In the modern era, one of the most active metaphors for the spiritual project is 'art'" (ibid). Art and spirit are again conjoined, although art's "spiritual project" is clearly intended to act as a proxy for religion; it is a "metaphor" for spirituality. This seems to have been Krauss's perspective. The grid's spare, geometric frame can 
become the armature for any number of spiritual, though not necessarily religious, connotations.

Perhaps this is the cardinal paradox of the grid: as a motif whose internal imperative is to repeat, it is taken up by the artist in each instance as a platform for new beginnings. If the windows by Richter and Hugonin are an extension of their painterly process, what is new, of course, is their context. The testimony of major new windows by Richter, Polke, Knoebel, and others, as well as humbler examples like Hugonin's, reinforces this idea of a reinvented spirituality through the use of abstraction in glass. Admittedly this is hardly new, or a new beginning; stained-glass windows in a modern style have been commissioned by the church for close to a century. Nevertheless, it is clear from the furore surrounding the Cologne commission that the abstract grid retains the ability to provoke and illuminate whenever it enters the church. Sontag's essay on silence concludes by reiterating the necessity for spirituality to be continually reinvented: "It is in the nature of all spiritual projects to tend to consume themselves," she says "exhausting their own sense, the very meaning of the terms in which they are couched" (33). When applied to church doctrine this can only be a highly questionable assertion. But when applied to art for the church it has a ring of truth. Back in 1975 Goldin's thoughts on the grid ended on an intriguing note, one which lends weight to continuing investigations of this particular visual form. The possibilities of rigid frameworks like the grid, she suggested, had generated innumerable artistic experiments, but little in the way of sustained thought. The pioneering work of Rosalind Krauss provided just such a framework for reflection, initiating the "reams and reams of artspeak" that followed, with unforeseen benefits for thinking through these visual tendencies in art for the church.

\section{Works Cited}

Beckett, Sister Wendy. Sister Wendy Beckett on Art and the Sacred. London: Rider Books, 1992.

Boehm, Gottfried et al. Sigmar Polke: Fenster-Windows Grossmünster Zürich. New York and Zürich: Parkett Publishers and Grossmünster Zürich, 2010.

Buchloh, Benjamin H. D. “The Chance Ornament: Aphorisms on Gerhard Richter's Abstractions.” Artforum 50:6 (2012): 168-179.

_-_. "Gerhard Richter, Cologne Cathedral." Artforum 46:4 (2007): 306-308, 376.

- - - "Richter's Abstractions: Silences, Voids, and Evacuations." Gerhard Richter: Paintings from 2003-2005. New York: Marian Goodman Gallery and Köln: Verlag der Buchhandlung Walther König, 2005. 7-27.

Bryars, Gavin. “Art \& Music.” Modern Painters 9:1 (1996): 72-73.

Dailey, Meghan. "Living Inside the Grid, New Museum of Contemporary Art." Artforum 41:9 (2003): 171-172.

Davey, Richard. "James Hugonin - Contrary Rhythm.” The Windows of St. John's Church. Healey, Northumberland: The Hotspur, 2010. 17-20.

Elderfield, John. “Grids.” Artforum 10:9 (1972): 52-59.

Elkins, James and David Morgan, eds. Re-Enchantment. New York and London: Routledge, 2009.

Eliade, Mircea. "The Sacred and the Modern Artist." Mircea Eliade: Symbolism, the Sacred, and the Arts. Ed. Diane Apostolos-Cappadona. New York: Crossroad, 1985. 81-85.

Goldin, Amy. "Patterns, Grids and Painting." Artforum 14:1 (1975): 50-54.

Harries, Richard. Art and the Beauty of God. London: Mowbray, 2000.

Hugonin, James. James Hugonin. Edinburgh: Ingleby Gallery, 2010.

_-_. James Hugonin. London: Serpentine Gallery, 1991. No page numbers.

-_- Repeat. London: Coracle Press, 1984. No page numbers.

Kemp, Martin. James Hugonin. Cambridge: Kettle’s Yard Gallery, 1996. No page numbers. 
Krauss, Rosalind. "The/Cloud/." Agnes Martin. Ed. Barbara Haskell. New York: Whitney Museum of American Art, 1992. 155-165.

- - . "The Originality of the Avant-Garde: A Postmodernist Repetition." October 18 (Fall 1981): 47-66.

. "Grids." October 9 (Summer 1979): 50-64.

Larner, Melissa, Rebecca Morrill, and Sam Phillips, eds. Gerhard Richter: 4900 Colours. London: Serpentine Gallery and Ostfildern: Hatje Cantz Verlag, 2008.

Linville, Kasha. "Agnes Martin: An Appreciation.” Artforum 9:10 (1971): 72-73.

Lippard, Lucy. "Top to Bottom, Left to Right." Grids Grids Grids Grids Grids Grids Grids Grids. Philadelphia: Institute of Contemporary Art, University of Pennsylvania, 1972. No page numbers.

Marion, Jean-Luc. Being Given: Toward a Phenomenology of Givenness. Stanford, CA: Stanford University Press, 2002.

McNamara, Andrew. "Between Flux and Certitude: The Grid in Avant-garde Utopian Thought." Art History 15:1 (1992): 60-79.

Mennekes, Friedhelm. "Lichtblicke in Köln." Stimmen der Zeit 226:1 (2008): 48-64.

Morley, Simon. "Light as Surface: On Recent British Abstract Painting." Contemporary Visual Arts 15 (1997): 30-37.

. "The Sublime and the Beautiful." Art Monthly 197 (1996): 14-16.

Museum Ludwig and Metropolitankapitel der Hohen Domkirche Köln (eds). Gerhard Richter: Zufall, the Cologne Cathedral Window, and 4900 Colours. Köln: Verlag der Buchhandlung Walther König, 2007.

Obrist, Hans Ulrich. “Gerhard Richter.” Domus 899 (2007): 116-125.

Richter, Gerhard. "Interview with Mark Rosenthal." Mark Rothko. National Gallery of Art, Washington. New Haven and London: Yale University Press, 1998. 363-366.

Rigney, Robert. "Let There Be Light." Art News 107:5 (2008): 46.

Sauerborn, Josef. "Window of the South Transept from Gerhard Richter." Web. 20 Nov. 2008 <www.koelner-dom.de/index.php?id=19152\&L=1>

Schulz, Martin. "Imi Knoebel's Windows in the Cathedral of Reims - Art in the Church, not Church Art." Imi Knoebel, Stained-Glass Windows in Reims Cathedral. Ed. Jean-Paul Ollivier. Bielefeld: Kerber Verlag, 2011. 56-57.

Sontag, Susan. Styles of Radical Will. London: Secker and Warburg, 1969 (1966).

South Bank Centre. The Experience of Painting: Eight Modern Artists. London: South Bank Centre, 1989.

Temkin, Ann. Color Chart: Reinventing Color, 1950 to Today. New York: The Museum of Modern Art, 2008.

Williams, Eliza. "Gerhard Richter: Serpentine Gallery, London." Flash Art 41:263 (2008): 86.

Yetton, Chris. "James Hugonin: Paintings 2004-2008." Building with Colour. Arts Gallery North Northumbria University, Newcastle-upon-Tyne: Arts and Social Sciences Academic Press, 2009. 7-9.

-. "The Abstract Ideal and the Sensual World." James Hugonin. Ed. Celia Davies. Bexhill on Sea: De La Warr Pavilion, 2006. 16-25. 